Belarus. Among the most important:

1. A shift in the planning and evaluation mechanism from a stiff, centralized control at the ministry to a more decentralized, faculty/professionally dominated one, with local or at least regionally based partial power of compromise and implementation.

2. A national faculty development program designed both to educate faculty as to new educational objectives, alternative modes of teaching, and new career paths. Faculty seem at the heart of the change process in Belarus. If the country is to develop into a democracy and free enterprise state, students must be enabled to grow and develop as unique individuals, not as tools of the state. The curriculum and extracurriculum must change accordingly. Moving from an objective of transmission of known truths through didactic means to an open, inquiring, questioning perspective will require much adjustment - and considerable faculty development. In the United States, new models of education are now finding their way into the design of institutions. These new models suggest that students must learn to develop a sense of self-identity, become more expressive, better able to relate to others, more willing to take risks, etc. To accomplish these ends in Belarus, new forms of instruction are necessary. Equally important, new forms ofinstitutionalized out-of-class activities must he set up to augment and support the classroominstruction. Further, the curriculum must shift from an emphasis on science and engineering to one favoring the preparation of students for entrepreneurial activity and business occupations.

3. A strengthening of the private higher education sector. Diversity is a prerequisite for change, since it breeds divergent thinking. Any country so dominated by a state system as Belarus will have difficulty encouraging innovation and change. There must be encouragement and support for private postsecondary education. The support may take many forms, including state financial aid to students for attendance at private institutions. The private system cannot he merely "parallel" or "peripheral," as in France and Sweden, hut instead, a significant and energizing force in the educational system. The very competition for students among the private institutions symbolizes a democratic/ capitalist system that should mirror the larger economic system for the country as a whole.

\title{
Developing a Canadian Science and Technology Strategy
}

\section{Glen A. Jones}

Glen A. Jones is Associate Professor, Higher Education Group, Ontario Institutefor Studies in Education, 252 Bloor Street West, Toronto, Ontario, CANADA Fax: 416-926-4725 E-Mail: giones@oje.on.ca

$\mathrm{C}$ anada has never really had a broad, national science and technology policy. While the federal government is the largest single source of support for university research, the vast majority of the government's activities in the area of science and technology has evolved from a diverse range of initiativesinvolving a wide range of federal departments and programs. A variety of departments operate research facilities or directly or indirectly support research activities, but, like many aspects of Canadian government activity, the approach has tended to be more sectoral and regional rather than national and comprehensive.

A national review of science and technology was initiated shortly after the election of a Liberal government in 1993, and led to the creation of a National Advisory Board on Science and Technology (NABST). The public consultation process involved the development of a series of background documents that provided a foundation for 25 community workshops, 5 regional conferences, and a national conference held in Ottawa at the end of 1994. Nineteen prominent individuals from industry, education, and research were appointed to the NABST, and their final report was released in April 1995.
The two external components of the review have served to highlight a number of important issues and questions concerning Canada's science and technology activities. While the federal government's expenditure on research and development as a percentage of GDP is roughly comparable with other nations in the Organisation for Economic Co-operation and Development (OECD) (though slightly lower), expenditures by industry are significantly lower than almost all of Canada's industrialized peers.

The final report of the NABST, entitled Healtby Wealtby and Wise,' notes that the federal government is now the "single largest performer" of science and technology in Canada. While the government spends approximately $\$ 980$ million supporting research performed by industry, and $\$ 950$ million supporting research performed by universities, over $\mathbf{\$ 3 , 4 0 0 m i l l i o n ~ i s ~ s p e n t ~ o n ~ r e s e a r c h ~ p e r f o r m e d ~}$ by government. These activities include the work of over 150 federal laboratories involving approximately 11,800 scientific or professional staff and 8,600 technicians.

Given these two findings, a central issue in the review process has involved attempting to articulate the role in science and technology that should be played hy government, industry, and the universities. In terms of the government role, there are major concernsthat at least some of the research activities performed hy government have 
not been subjected to the accountability mechanisms associated with either market forces or traditional scholarship (external peer review). The NABST report argues that at least some of these activities would he best performed by either universities or industry, that all government research programs should be regularly reassessed, and that government should only perform science in those "areas of need where only the government can and should act" (such as national security, regulatory requirements, standards, national data collection, etc.).

\begin{abstract}
The comparatively small investment on the part of private industry in research and development is highlighted in almost all of the various reports emanating from the review process.
\end{abstract}

The report also calls on government to playa larger role in establishing national objectives, promoting and coordinating research and development activities, strengthening the role of science in education, and supporting the research and development activities of both the universities and industry.A particularly important series of recommendations encourages the government to invest more funds in social science research related to program evaluation and the search for more effective and efficient ways of delivering government programs. The comparatively smallinvestment on the part ofprivate industryin research and development is highlighted in almost all of the various reports emanating from the review process. Encouraging the private sector to strengthen its investment in science, technology, and innovation is a key theme.

Aside from the traditional conclusion that university-industry linkages should be strengthened, the discussion of university performance in science and technology has been unusually complimentary. Comparative international data supports the conclusion that, despite limited government support, Canadian universities are productive research enterprises. The various reports serve to reinforce the central role of the university in educating future researchers and conducting pure (or "researcher-initiated") and applied research.

Like many contemporary studies on this theme, the review process has heen clothed in the rhetoric of globalization and international competitiveness, but within that skin of warm clichés are a number of important and revealing observations. First, it appears clear that the Government of Canada has failed to hold its own departments accountable for performance in science and technology and that policies designed to encourage "contracting out" of research activities have heen ignored within government. One likely result of the review process will he a complete overhaul of government research laboratories (especially for a government struggling to find ways of reducing expenditures) and the development of external peer review mechanisms comparable with the more traditional scholarly community.

Second, for a review of science and technology, an unusually heavy emphasishas been placed on the social sciences. A central assumption in the report is that many of the central questions that must be addressed if Canada is to strengthen its capacity to advance knowledge and improve the quality of life of its citizens are really in the domain of the social sciences. The recent NABST report also recommends that government-held data be made more accessible to researchers and students.

Third, the context of discussions has expanded beyond the language of global competitiveness and industrial development. While the NABST report includes a chapter on "Wealth and Job Creation in the Context of SustainableDevelopment," the concluding chapter focuses on "The Advancement of Knowledge," and an early chapter discusses the role of science and technology policy in terms of the "Quality of Life."

Whether this review process will actually lead to the development of a comprehensive national strategy for science and technology is difficult to predict. Considerable time and energy have already been invested in the process, and this fact, combined with the level of debate that the review process has catalyzed within universities, government, and at least some sectors of industry, may create the momentum necessary to sustain the process through to its logical end. On the other hand, the process has received extremelylittle coveragein the national media, and the federal cabinet's attention has been focusing on a variety of controversial issues, including gun control legislation and deficitreduction strategies, and the government must now prepare for the upcoming referendum in Quebec on separation. It is clear, however, that this review process has been successful in terms of confronting and addressing a number of extremely important issues. The quality of debate in this policy arena has been unusually high, and the research and documents produced for the review have already increased our understanding of this complex area of public policy.

The report is available electronically via the World Wide Web (http://infoic.gc.ca/opengov/nobst/nobst.html) or cop ies can be requested by email (ñobst@ic.gc.ca). 